\title{
Association of family risk and lifestyle/comorbidities in ovarian cancer patients
}

\author{
Natália Teixeira ${ }^{1 *}$, Maria Aparecida Azevedo Koike Folgueira ${ }^{2}$, Simone Maistro ${ }^{3}$, Giselly Encinas ${ }^{4}$, Geertruida Hendrika de Bock ${ }^{5}$, \\ Maria Del Pilar Estevez Diz ${ }^{6}$

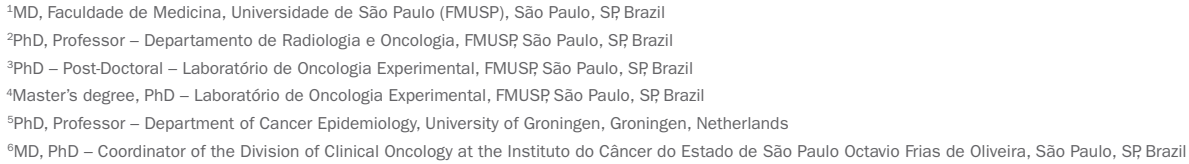

Study conducted at Instituto do Câncer do Estado de São Paulo (ICESP), São Paulo, SP, Brazil

Article received: 6/4/2014 Accepted for publication: 10/21/2014

*Correspondence: Address: Av. Dr. Arnaldo, 251 Cerqueira César São Paulo, SP - Brazil Postal code: 01255-000 natalia.teixeira@usp.br

Financial support: CNPq

http://dx.doi.org/10.1590/1806-9282.61.03.234 Conflict of interest: none

\section{SUMMARY}

Objectives: to analyze factors that might indicate familial predisposition for ovarian cancer in patients diagnosed with this disease.

Methods: in a prospective single center cohort study at the Institute of Cancer of the State of São Paulo (ICESP), 51 women diagnosed with ovarian cancer were included. Familial predisposition for ovarian cancer was defined as having a higher than $10 \%$ chance of having a BRCA1/2 mutation according to the Manchester scoring system, a validated method to assess the likelihood of mutation detection. Each patient was interviewed with a standardized questionnaire on established risk factors for ovarian cancer and other factors that might influence the risk to develop ovarian cancer. Logistic regression analyses were performed to estimate the impact of the evaluated factors on the likelihood of mutation detection, by calculating odds ratios and $95 \%$ confidence intervals.

Results: seventeen out of 51 patients had a family history of breast and/or ovarian cancer, four patients had a history of breast or endometrial cancer, 11 were diagnosed before the age of 50, and 12 presented a risk of familial predisposition to ovarian cancer higher than $10 \%$. Patients with comorbidities, such as hypertension, diabetes, hormonal disorders, dyslipidemia and psychiatric conditions, presented a lower chance of having a familial predisposition for ovarian cancer (OR: 0.22; 95\% CI: 0.06-0.88; $\mathrm{p}=0.03$ ).

Conclusion: in this study, having comorbidities was associated with a lower risk of having a familial predisposition for ovarian cancer. Other factors associated with the risk of ovarian cancer did not have an impact on this predisposition.

Keywords: ovarian neoplasms, hereditary breast and ovarian cancer syndrome, neoplastic syndromes, hereditary, risk factors.

\section{INTRODUCTION}

Ovarian cancer is one of the most common gynecological malignancies. In Brazil, 6,190 new cases were estimated for the year 2012, 28\% of which, in the state of São Paulo. ${ }^{1}$ It is the eighth most common cancer ${ }^{2}$ and the sixth cancer-related cause of death ${ }^{3}$ among women in the state of São Paulo. Most cases are diagnosed at advanced stages, associated with a 5 -year survival rate as low as $32 \%{ }^{4}$ The delay on diagnosis occurs mainly due to lack of symptoms in early stages and early spreading of the disease.
Approximately 5 to $10 \%$ of all ovarian cancer cases have a genetic predisposition, most often related to a $B R C A 1$ or $B R C A 2$ gene mutation. Women who carry a mutation have a significantly increased risk of developing the disease. The cumulative incidence of ovarian cancer at age 70 is estimated to be $40 \%$ (95\% CI: $35-46 \%$ ) in BRCA1 mutation carriers and 18\% (95\% CI: 13-23\%) in BRCA2 mutation carriers. ${ }^{5}$ The estimate was based on a meta-analysis of ten studies addressing BRCA1/2 penetrance. Great heterogeneity was observed among reported risks on the 
studies, as risks vary depending on the population studied and ascertainment method. The ten studies included in the meta-analysis were performed in the United States, England, Australia and Italy.

There are no studies addressing specifically family predisposition or $B R C A 1 / 2$ mutations in ovarian cancer patients in Brazil and, despite the importance of this disease for public health, the country lacks precise national epidemiologic data on it. Hence the prevalence of BRCA1/2 mutations in the Brazilian population and the risk of these women developing ovarian cancer have not yet been well established.

Since the availability of genetic testing is very limited in Brazil, a preliminary step would be to characterize family history and predisposing factors associated with high risk of ovarian cancer in the Brazilian women. It would be important to have more information on ovarian cancer patients, analyzing possible factors that might indicate a genetic predisposition to the disease, as well as other factors that could impact ovarian cancer risks. With that information, we would be able to estimate cancer risks more precisely, providing women with more individualized counseling. These women could be referred to a geneticist, who could provide family counseling, proposing screening and preventive measures for unaffected family members. ${ }^{6}$ Such personalized care is very important considering the life changing decisions that women at high risk for breast and ovarian cancer must make regarding cancer prevention. ${ }^{7-9}$

This study aimed at characterizing women with ovarian cancer in Brazil. Another aim was to test the association of predisposing factors to ovarian cancer with the risk of having a hereditary predisposition for the disease. Identifying factors associated with a higher risk of familial predisposition for cancer would be of great value for physicians who treat ovarian cancer patients with limited access to genetic testing.

\section{Methods}

\section{Patients}

In a prospective, single-center cohort study, patients diagnosed with ovarian cancer that were undergoing either treatment or follow-up at the Institute of Cancer of São Paulo (ICESP) were invited to participate in this study. Inclusion criteria were: pathology report confirming epithelial ovarian cancer, age older than 18 and diagnosis of primary tumor between 2009 and 2012. Exclusion criteria were: borderline tumors (except cases with invasive areas), benign lesions, cases of metastatic tumors from other primary sites and tumors diagnosed before 2009. This study was approved by the Institutional Ethics Committee and, after explanation of its purposes, patients who agreed on participating signed an informed consent form.

\section{Questionnaire}

A questionnaire covering demographic characteristics, anthropometric measures, hormonal exposure during life, life habits, tumor characteristics, and family history of cancer was developed for this study (Table 1). A pilot study was performed including four patients in order to improve both the questionnaire and the inquiry methods. After receiving a detailed explanation of the study, each patient answered all questions made by the interviewer, who filled in the questionnaires. All patients were interviewed by the same person. The interviews were all performed in a private room and patients were guaranteed the confidentiality of their information. From family history information, a pedigree was drawn for each patient included in this study. All information obtained was entered into an SPSS version 20.0 database for further analysis.

\section{Outcomes}

Based on information gathered regarding family history and age of onset of tumors in the patients themselves and/or family members, the likelihood of having a familial predisposition for ovarian cancer, which might be associated with the presence of a genetic mutation, was calculated for each patient using the Manchester scoring system, ${ }^{10}$ which is based on the patient's personal and family history of cancer. This system is relatively simple compared to computer models used to access mutation detection likelihood, and it substantially outperforms them when assessing the risk of familial predisposition to breast or ovarian cancer. ${ }^{10}$

\section{Analysis}

To assess the relation between factors covered by the questionnaire and the strengths of having a familial predisposition for ovarian cancer according to the Manchester scoring system, patients were divided into two groups: those with a $10 \%$ or higher likelihood of having a familial predisposition and those with a lower than $10 \%$ likelihood. For this analysis, logistic regression was applied in order to obtain the odds ratio (OR) and $95 \%$ confidence interval $(95 \% \mathrm{CI})$. All tests were two sided and $\mathrm{p}<0.05$ was considered statistically significant.

\section{Results}

The questionnaire was administered to 59 patients from our outpatient clinic. Of this total, 51 patients with in- 
vasive carcinomas were included (Table 1): 42 serous adenocarcinomas, 6 endometrioid adenocarcinomas, 1 mucinous adenocarcinoma, 1 mixed mullerian adenocarcinoma and 1 borderline tumor with invasive areas. Eight patients were excluded: a borderline tumor (1), a benign lesion (1), metastasis from other primary sites (2), recurrence of a tumor diagnosed before 2009 (4).

\section{TABLE 1 Patients' characteristics.}

\begin{tabular}{ll} 
Age (current) - median (min-max) & $57(36-76)$ \\
\hline BMI - median (min-max) & $27.9(17.8-39.7)$ \\
\hline Menarche (age) - median (min-max) & $13.0(9-17)$ \\
\hline Menopause (age) - median (min-max) & $48.0(35-60)$ \\
\hline $\begin{array}{l}\text { Use of oral contraceptives (months) - median } \\
\text { (min-max) }\end{array}$ & $12(0-144)$ \\
\hline Full term pregnancies - median (min-max) & $2(0-15)$ \\
\hline Breast feeding (months) - median (min-max) & $2(0-168)$ \\
\hline Age at diagnosis - median (min-max) & $55.0(34-73)$ \\
\hline Tumor type & 42 \\
$\quad$ Serous adenocarcinoma & 6 \\
Endometrioid adenocarcinoma & 1 \\
Mucinous adenocarcinoma & 1 \\
Mixed Mullerian adenocarcinoma & 1 \\
Borderline tumor with invasive areas &
\end{tabular}

Of the 51 patients included in the analysis, 32 reported previous oral contraceptive use and 11 informed no previous pregnancies (Table 1). Only five of these patients had not been submitted to an oophorectomy until the moment of the interview. Four patients had been previously diagnosed with other primary tumors besides ovarian cancer: three had breast cancer and one had endometrial cancer.

Regarding family history, ten patients reported having at least one first-degree relative with breast or ovarian cancer. When we included also second-degree relatives in the pedigree chart, the number increased to seventeen. Three of the patients interviewed had no contact with their families and had no information about their relatives' causes of death. From all patients included in this study, 11 were diagnosed with ovarian cancer before age 50 years, while 40 were fifty or older at the diagnosis. When calculating the likelihood of familial predisposition for cancer, 12 patients had a higher than $10 \%$ risk of having a familial predisposition for the disease, while in 39 patients this risk was lower than $10 \%$ (Table 2).

From all variables covered by the questionnaire, having comorbidities was more frequent among patients with a likelihood of familial predisposition lower than
TABLE 2 patients risk factors for ovarian cancer.

\begin{tabular}{ll} 
Family history & N \\
\hline No breast or ovarian cancer in $1^{\text {st }}$ degree relatives & 39 \\
\hline Breast or ovarian cancer cases in $1^{\text {st }}$ degree relatives & 10 \\
\hline Age at diagnosis of ovarian cancer & 11 \\
\hline Before age 50 & 40 \\
\hline At age 50 or older \\
\hline $\begin{array}{l}\text { Risk of mutation detection according to Manchester } \\
\text { score }\end{array}$ \\
\hline Lower than $10 \%$ & 39 \\
\hline 10\% or higher & 12 \\
\hline
\end{tabular}

$10 \%$ compared to patients in which this likelihood was $10 \%$ or higher (69.2 vs. $33.3 \%$, OR: 0.22 , $95 \%$ CI: $0.06-0.88$ ) (Table 3).

\section{Discussion}

In this study, we assessed the relation between clinical and demographic characteristics of patients diagnosed with ovarian cancer and having an increased risk for a familial predisposition to ovarian cancer, based on personal and family history of cancer. We observed a significantly higher frequency of comorbidities among women with a lower than $10 \%$ chance of having a familial predisposition for ovarian cancer. All other factors evaluated by this study did not present a significant correlation with the risk of having such genetic predisposition.

There are very few studies in the literature addressing the correlation between clinical characteristics of breast and ovarian cancer patients and their likelihood of harboring BRCA1/2 mutation, all of them in breast cancer patients/ family members. Our findings are in line with previous studies addressing this topic. ${ }^{11-13}$ Atchley et al. evaluated clinical and pathological characteristics of patients with BRCApositive and -negative breast cancer and found that well established risk factors did not differ between women with or without BRCA mutations and that ethnic background was similar among mutation carriers and noncarriers. ${ }^{11}$ Later on, in a multivariate logistic model, Bayraktar et al. evaluated women with ductal carcinoma in situ, finding that a family history of at least 2 family members with ovarian cancer was significantly associated with a higher rate of $B R C A$ positivity regardless of age at diagnosis (OR 8,81). ${ }^{12}$ Previously, in a study that aimed at finding associations between clinical characteristics and positive mutation status in Finnish breast cancer families, Vahteristo et al had also observed that the number of ovarian cancer cases in a family, as well as the age of the youngest breast cancer case were independent predictors of $B R C A$ mutations. ${ }^{13}$ 
TABLE 3 Patients' characteristics compared to likelihood of BRCA1/2 mutation detection.

\begin{tabular}{|c|c|c|c|c|c|}
\hline \multirow[t]{2}{*}{ Variable } & & \multicolumn{4}{|c|}{ Likelihood of BRCA1/2 mutation detection } \\
\hline & & lower than $10 \%(n=39)$ & higher than $10 \%(n=12)$ & OR $(95 \% \mathrm{CI})$ & $P$ value \\
\hline \multirow[t]{2}{*}{ Histopathology } & Serous adenocarcinoma & $31(79.5 \%)$ & $11(91.7 \%)$ & 1 & 0.35 \\
\hline & Others & $8(20.5 \%)$ & $1(8.3 \%)$ & $0.35(0.04-3.15)$ & \\
\hline \multirow[t]{2}{*}{$\mathrm{BMI}$} & Up to 30 & $28(1.8 \%)$ & $6(54.5 \%)$ & 1 & 0.28 \\
\hline & 30 or more & $11(28.2 \%)$ & $5(45.5 \%)$ & $2.12(0.53-8.40)$ & \\
\hline \multirow[t]{2}{*}{ Menarche } & Up to 14 years of age & $30(78.9 \%)$ & $10(83.3 \%)$ & 1 & 0.74 \\
\hline & 14 years of age or older & $8(21.1 \%)$ & $2(16.7 \%)$ & $0.75(0.14-4.13)$ & \\
\hline \multirow[t]{2}{*}{ Menopause } & Under 50 yers of age & $25(64.1 \%)$ & $8(66.7 \%)$ & 1 & 0.87 \\
\hline & Older than 50 years of age & $14(35.9 \%)$ & $4(33.3 \%)$ & $0.89(0.23-3.50)$ & \\
\hline \multirow[t]{2}{*}{ Menstrual cycle } & $<26$ days & $6(18.2 \%)$ & $1(8.3 \%)$ & 1 & 0.43 \\
\hline & $\geq 26$ days & $27(81.8 \%)$ & $11(91.7 \%)$ & $2.44(0.26-22.73)$ & \\
\hline Use of oral & Up to 2 years & $28(73.7 \%)$ & $7(58.3 \%)$ & 1 & 0.32 \\
\hline contraceptives & 2 years or more & $10(26.3 \%)$ & $5(41.7 \%)$ & $2.00(0.51-7.76)$ & \\
\hline \multirow[t]{2}{*}{ Children } & Up to 1 child & $18(46.2 \%)$ & $2(16.7 \%)$ & 1 & 0.08 \\
\hline & More than 1 child & $21(53.8 \%)$ & $10(83.3 \%)$ & $4.29(0.83-22.17)$ & \\
\hline Age at first & Younger than 25 & $15(53.6 \%)$ & $8(72.7 \%)$ & 1 & 0.28 \\
\hline pregnancy & 25 or older & $13(46.4 \%)$ & $3(27.3 \%)$ & $0.43(0.09-1.98)$ & \\
\hline \multirow[t]{2}{*}{ Breast feeding } & Up to 12 months & $25(64.1 \%)$ & $6(50 \%)$ & 1 & 0.38 \\
\hline & More than one year & $14(35.9 \%)$ & $6(50 \%)$ & $1.79(0.48-6.60)$ & \\
\hline \multirow[t]{2}{*}{ Comorbidities } & No & $12(30.8 \%)$ & $8(66.7 \%)$ & 1 & 0.03 \\
\hline & Yes & $27(69.2 \%)$ & $4(33.3 \%)$ & $0.22(0.06-0.88)$ & \\
\hline Age at diagnosis & 50 or younger & $8(20.5 \%)$ & $3(25 \%)$ & 1 & 0.74 \\
\hline of ovarian cancer & Older than 50 & $31(79.5 \%)$ & $9(75 \%)$ & $0.77(0.17-3.54)$ & \\
\hline \multirow[t]{2}{*}{ Family history } & No & $34(94.4 \%)$ & $4(33.3 \%)$ & 1 & 0.00 \\
\hline & Yes & $2(5.6 \%)$ & $8(66.7 \%)$ & $34(5.27-219.27)$ & \\
\hline
\end{tabular}

Regarding age at cancer diagnosis, previously published studies show contradictory results. There are studies reporting a higher rate of mutation detection in women diagnosed with breast cancer at younger age ${ }^{14}$ and others that show similar mutation rates among younger and older patients. ${ }^{12,15,16}$ In this study we found no correlation between age at diagnosis of ovarian cancer and probability of familial predisposition for cancer.

Furthermore, there are studies aiming at identifying tissue-based predictors of mutations in patients with breast cancer. De la Cruz et al. found that estrogen receptor positive phenotype was inversely associated with the presence of BRCA1 mutation (OR 0.24) and that high mitotic activity was directly associated with BRCA1 mutation (OR 4.22). ${ }^{6}$ In our study, we found no evidence of association between tumor type and risk of mutation detection. We did not access other pathological characteristics of the tumors.

The main outcome in this study was the association of clinical and demographic factors with the risk of hav- ing a familial predisposition for ovarian cancer. In order to access the likelihood of having such familial predisposition in our patients, we used the Manchester scoring system, ${ }^{10}$ which is based on the patient's personal and family history of cancer to predict the risk of finding $B R C A 1$ or $B R C A 2$ mutations. There are several studies aiming at predicting the probability of a genetic predisposition to breast and ovarian cancer in individuals or families. ${ }^{17-19}$ These studies resulted in the development of advanced computer prediction models that rely mostly on family history of breast and ovarian cancer, tumor characteristics and age at diagnosis. The Manchester scoring system is simpler than the aforementioned computer mutation prediction model. The main reason for choosing such scoring system was that information on family history is often incomplete and not always accurate, making it difficult to fill in the information required by these models correctly, which could lead to unreliable results. DNA analysis on blood samples would provide more accurate information on genetic predisposition for cancer 
and would be the preferred method on such analysis. However, since DNA analysis is not yet available through the Brazilian public healthcare system, this scoring system is the second best option.

Our results must be interpreted in light of the limitations of this study. Our main limitations are the small number of patients enrolled and their difficulties to recall family history. In Brazil, especially for older generations, many deaths are left undiagnosed. There are many individuals who migrated to/from different areas of the country and have little contact with their relatives. These facts probably lead to a considerable amount of missing relatives in the pedigrees, which maybe could lead us to underestimate the risk of familial predisposition to cancer. It is also important to take into account that the model we applied is not validated in this population and it is not completely sensitive and specific for the presence of a mutation, hence genetic testing should be performed in the future for more accurate information. Since we have no DNA analysis, it was not possible to study the impact of the factors evaluated by this study on the rates of mutation detection, which would be very enriching in this analysis. The strong points of our study are that all patients included were followed at the same hospital and pathology reports from all patients were available, as well as the fact that all patients were interviewed by the same person.

\section{Conclusion}

In this study, we found that having comorbidities is associated with a lower risk of having familial predisposition for cancer. Other factors associated with the risk of ovarian cancer did not have an impact on the likelihood of heredity of the cancer. Considering that currently available screening strategies are not effective ${ }^{6-7}$ and that risk reducing salpingo-oophorectomy (RRSO) significantly lowers ovarian cancer risks ${ }^{8-9}$ by detecting women with a higher risk of developing ovarian cancer, providing them counseling over risk reduction measures is essential for preventing this disease in this group of high risk women. Since the currently available prediction models are not very specific and sensitive, and not so widely available for clinicians, further studies are needed to evaluate other factors associated with ovarian cancer that might be associated with the probability of familial cancer.

\section{Resumo}

Associação de história familiar e estilo de vida a comorbidades em pacientes com câncer de ovário.
Objetivos: analisar fatores que possam indicar uma predisposição familiar ao câncer de ovário em pacientes com este diagnóstico.

Métodos: em estudo de coorte prospectiva realizado no Instituto do Câncer do Estado de São Paulo (ICESP), foram incluídas 51 mulheres diagnosticadas com câncer de ovário entre janeiro de 2009 e dezembro de 2011. Predisposição familiar para câncer de ovário foi definida como um risco maior de $10 \%$ de apresentar uma mutação em BRCA1/2, de acordo com o sistema de pontes de Manchester, um método validado para avaliar a probabilidade de detecção de mutação nesses genes. Cada paciente foi entrevistada com um questionário padronizado, abordando fatores de risco para câncer de ovário e outros fatores que pudessem influenciar o risco de desenvolver a doença. O impacto dos fatores avaliados na probabilidade de detecção da mutação foi avaliado com regressões logísticas.

Resultados: dezessete das 51 pacientes referiram história familiar de câncer de mama e/ou ovário, quatro pacientes apresentavam antecedente pessoal de câncer de mama ou endométrio, 11 haviam sido diagnosticadas antes dos 50 anos e 12 apresentaram um risco maior que $10 \%$ de predisposição familiar a câncer de ovário. Pacientes com comorbidades como hipertensão, diabetes, disfunções hormonais, dislipidemia e distúrbios psiquiátricos apresentaram menor risco de predisposição familiar ao câncer de ovário (OR: 0.22; IC 95\%: 0.06-0.88; $\mathrm{p}=0.03$ ). Conclusão: neste estudo, apresentar alguma comorbidade foi associado a um menor risco de ter uma predisposição familiar ao câncer de ovário. Outros fatores associados ao risco de câncer de ovário não tiveram nenhum impacto sobre esta predisposição.

Palavras-chave: neoplasias ovarianas, fatores de risco, síndromes neoplásicas hereditárias.

\section{REFEREnCES}

1. Secretaria do Estado da Saúde do Governo do Estado de São Paulo. Cancer incidence estimates. Available at: http://portal.saude.sp.gov.br/resources/ ses/perfil/gestor/homepage/estimativas-de-incidencia-de-cancer-2012/ estimativas_incidencia_cancer_2012.pdf [Accessed February 2014].

2. Fundação Oncocentro de São Paulo. Ovarian cancer incidence data. Available at: http://www.fosp.saude.sp.gov.br/ [Accessed January 2013].

3. Fundação Oncocentro de São Paulo. Ovarian cancer mortality data for 2007/2008 (source: DATASUS). Available at: http://www.fosp.saude.sp.gov. br/ [Accessed January 2013].

4. Howlader N, Noone AM, Krapcho M, Garshell J, Neyman N, Altekruse SF, et al. (eds.). SEER Cancer Statistics Review, 1975-2010, National Cancer Institute. Bethesda, MD, http://seer.cancer.gov/csr/1975_2010/, based on November 2012 SEER data submission, posted to the SEER web site, April 2013.

5. Chen S, Parmigiani G. Meta-analysis of BRCA1 and BRCA2 penetrance. J Clin Oncol. 2007; 25(11):1329-33. 
6. Eitan R, Michaelson-Cohen R, Levavi H, Beller U. The counseling and management of young healthy BRCA mutation carriers. Int J Gynecol Cancer. 2009; 19(7):1156-9.

7. Stan DL, Shuster LT, Wick MJ, Swanson CL, Pruthi S, Bakkum-Gamez JN Challenging and complex decisions in the management of the BRCA mutation carrier. J Womens Health (Larchmt). 2013; 22(10):825-34.

8. Howard AF, Balneaves LG, Bottorff JL, Rodney P. Preserving the self: the process of decision making about hereditary breast cancer and ovarian cancer risk reduction. Qual Health Res. 2011; 21(4):502-19.

9. Howard AF, Bottorff JL, Balneaves LG, Kim-Sing C. Women's constructions of the 'right time' to consider decisions about risk-reducing mastectomy and risk-reducing oophorectomy. BMC Womens Health. 2010; 10:24.

10. Evans DGR, Eccles DM, Rahman N, Young K, Bulman M, Amir E, et al. A new scoring system for the chances of identifying a BRCA1/2 mutation outperforms existing models including BRCAPRO. J Med Genet. 2004; 41(6):474-80

11. Atchley DP, Albarracin CT, Lopez A, Valero V, Amos CI, Gonzalez-Angulo AM, et al. Clinical and pathologic characteristics of patients with BRCA-positive and BRCA-negative breast cancer. J Clin Oncol. 2008; 26(26):4282-8.

12. Bayraktar S, Elsayegh N, Gutierrez Barrera AM, Lin H, Kuerer H, Tasbas T, et al. Predictive factors for BRCA1/BRCA2 mutations in women with ductal carcinoma in situ. Cancer. 2012; 118(6):1515-22.
13. Vahteristo P, Eerola H, Tamminen A, Blomqvist C, Nevanlinna H. A probability model for predicting BRCA 1 and BRCA2 mutations in breast and breast-ovarian cancer families. Br J Cancer. 2001; 84(5):704-8.

14. Hall MJ, Reid JE, Wenstrup RJ. Prevalence of BRCA1 and BRCA2 mutations in women with breast carcinoma in situ and referred for genetic testing. Cancer Prev Res (Phila). 2010; 3(12):1579-85

15. Smith KL, Adank M, Kauff N, Lafaro K, Boyd J, Lee JB, et al. BRCA mutations in women with ductal carcinoma in situ. Clin Cancer Res. 2007; 13(14):4306-10.

16. Hartge P, Streuwing JP, Wacholder S, Brody LC, Tucker MA. The prevalence of common BRCA1 and BRCA2 mutations among Ashkenazi Jews. Am J Hum Genet. 1999; 64(4):963-70

17. Antoniou AC, Pharoah PD, McMullan G, Day NE, Stratton MR, Peto J, et al. A comprehensive model for familial breast cancer incorporating BRCA1, BRCA2 and other genes. Br J Cancer. 2002; 86(1):76-83.

18. Parmigiani G, Berry D, Aguilar O. Determining carrier probabilities for breast cancer-susceptibility genes BRCA1 and BRCA2. Am J Hum Genet. 1998; 62(1):145-58

19. Frank TS, Deffenbaugh AM, Reid JE, Hulick M, Ward BE, Lingenfelter B, et al. Clinical characteristics of individuals with germline mutations in BRCA1 and BRCA2: analysis of 10,000 individuals. J Clin Oncol. 2002; 20(6):1480-90. 